\title{
Obduksjonens betydning for registrering av dødsårsak
}

\section{Sammendrag}

Bakgrunn. Ved mer enn $90 \%$ av dødsfallene i Norge er dødsmeldingen eneste informasjonskilde for registrering av underliggende dødsårsak. Ved bare en liten andel av tilfellene foreligger det tilleggsinformasjon, som regel fra sykehusobduksjon eller rettslig obduksjon. Vi ønsket å undersøke hvor hyppig funn ved sykehusobduksjon påvirker fastsettelsen av underliggende dødsårsak.

Materiale og metode. Med utgangspunkt i Dødsårsaksregisteret bestemte vi ut fra dødsmeldingen underliggende dødsårsak for dødsfall der det ble utført sykehusobduksjon i 2005. Deretter undersøkte vi om underliggende dødsårsak ble endret når vi tok hensyn til obduksjonsfunnene.

Resultater. I 2005 var det 41152 dødsfall i Norge. Dødsårsaksregisteret mottok resultat av sykehusobduksjon for 1773 døde, med alder fra to år og oppover. Obduksjonsfunn førte til endring av underliggende dødsårsak for 1077 (61\%) dødsfall. For 567 dødsfall (32\%) var endringen stor og medførte skifte av ICD-10-kapittel for dødsårsaken. Andelen endrede dødsårsaker var større i de yngste og de eldste aldersgruppene og for kvinner.

Fortolkning. Sykehusobduksjon er et viktig korrektiv når det gjelder fastsetting av underliggende dødsårsak.

\section{G. Cecilie Alfsen}

cecilie.alfsen@medisin.uio.no

Avdeling for patologi

Akershus universitetssykehus

Medisinsk fakultet

Universitetet i Oslo

\section{Jan Mæhlen}

Avdeling for patologi

Oslo universitetssykehus, Ullevål og

Medisinsk fakultet

Universitetet i Oslo

og

Dødsårsaksregisteret

Nasjonalt folkehelseinstitutt

Dødsårsaksstatistikken er viktig for overvåking av folkehelsen. God kvalitet på denne statistikken krever at legene vektlegger korrekt utfylling av dødsmeldingen og at de har forståelse for årsaken bak dødsfallet (1).

Obduksjon er en medisinsk undersøkelse som foretas for å bestemme underliggende dødsårsak og for å kvalitetssikre den medisinske behandlingen pasienten har fått. Obduksjonens betydning for dødsårsaksstatistikken blir med jevne mellomrom omtalt og diskutert i Tidsskriftets spalter (2-4). Eldre studier fra USA og Europa har vist at det i opp mot halvparten av dødsfallene er manglende samsvar mellom det som står på dødsmeldingen og obduksjonsresultatet $(5,6)$. Vi ønsket å undersøke om dette er endret. Formålet med denne studien var således å undersøke hva obduksjonsfunnene betyr for bestemmelse (ICD-10-koding) av tilgrunnliggende dødsårsak og om eventuelle forskjeller er kjønnseller aldersbestemt. Tilsvarende studier er ikke tidligere utført i Norge.

\section{Materiale og metode}

Data for studien er basert på «Legeerklæring om dødsfall/melding om unaturlig dødsfall» (heretter kalt dødsmelding). I rubrikk I skal utfyllende lege anføre sekvensen av sykelige tilstander, skade eller funksjonsnedsettelser som førte til døden. Ia angir umiddelbar dødsårsak, for eksempel lungeemboli, Ib angir mellomliggende dødsårsak, for eksempel leggvenetrombose, og Ic angir tilgrunnliggende dødsårsak, for eksempel kreft i bukspyttkjertelen. Den nederste diagnosen i rubrikk I vil vanligvis bli registrert som underliggende dødsårsak. Det er ofte ikke nødvendig å benytte alle tre feltene. I rubrikk II kan legen anføre andre vesentlige tilstander som kan ha bidratt til den dødelige utgang, men som ikke sto i direkte årsaksforhold til sykdomssekvensen i posisjon I.

For å korrigere åpenbare feil og logiske brudd som er gjort av legen ved utfylling av dødsmeldingen, har Verdens helseorganisasjon (WHO) utarbeidet et sett med regler som styrer hvordan Dødsårsaksregisteret bestemmer underliggende dødsårsak ut fra dødsmeldingen. Frem til 2005 ble underliggende dødsårsak bestemt manuelt av kodepersonalet ved Dødsårsaksregisteret, men fra 2005 bestemmes den elektronisk ved hjelp av et dataprogram (Automated Classification of Medical Entities, ACME), som er utviklet av National Center for Health Statistics i USA (7). Programmet krever at dødsmeldingen «oversettes» til ICD-10-koder (International Classification of Diseases, versjon 10) (8). Denne oversettelsen gjøres av kodepersonalet. ACME-programmet «leser» deretter den kodede dødsmeldingen og bestemmer underliggende dødsårsak.

I tillegg til dødsmeldingene mottar Dødsårsaksregisteret resultatene av alle obduksjoner. Obduksjonsdiagnosene vil oftest være ført opp på samme måte som diagnosene på dødsmeldingen, men diagnosene vil oftere være basert på de morfologiske forandringer som sykdommen eller skaden har forårsaket.

Når det foreligger både dødsmelding og resultat av sykehusobduksjon, må det bestemmes manuelt hvilket oppsett av ICD10-koder som skal analyseres av ACMEprogrammet. Med bakgrunn i tilleggsfunn ved obduksjonen konstrueres det ved Dødsårsaksregisteret dermed en «kombinert» dødsmelding som kan inneholde diagnoser både fra dødsmeldingen og fra obduksjonen. I de fleste tilfeller vil vurderingen være at obduksjonsresultatene har forrang, men i mange tilfeller blir flere av diagnosene på dødsmeldingen tatt med, selv om de ikke står oppført i obduksjonsrapporten.

\section{Hovedbudskap}

- Obduksjon gir et viktig korrektiv til dødsmeldingen

- Fallende antall sykehusobduksjoner kan medføre endret sammensetning av dødsårsaker

- Tiltak for å øke antall obduksjoner og andre tiltak for å forbedre dødsårsaksregistreringen bør overveies 
For alle som undergikk sykehusobduksjon i 2005 fikk vi tilgang til ICD-10-koder for underliggende dødsårsak bestemt ut fra de originale dødsmeldingene og de «kombinerte» dødsmeldingene, som inkluderte obduksjonsdiagnoser samt kjønn og alder. Fordi det ved registrering av dødsårsak ved perinatale dødsfall også benyttes opplysninger fra Medisinsk fødselsregister, ble ikke dødsfall hos personer under to år vurdert.

Opplysninger om underliggende dødsårsak, kjønnsfordeling og alder ved død for hele befolkningen ble hentet fra offisiell statistikk i Statistisk sentralbyrå. Alle statistiske analyser av forskjeller mellom de originale dødsmeldingene og de «kombinerte» dødsmeldingene ble utført med PASW statistics 18. Det ble benyttet khikvadrattest for vurdering av alders- og kjønnsforskjeller og forskjeller i ICD-10-koder. Materialet ble inndelt i fem aldersgrupper: $2-30$ år, 31-50 år, 51-70 år, 71-90 år og > 90 år. P-verdier $<0,05$ ble ansett som statistisk signifikante. Alle data var anonymisert, undersøkelsen var således ikke fremleggelsespliktig for regional etisk komité.

\section{Resultater}

Av 1773 obduserte i alderen to år og oppover i 2005 var det 989 menn og 784 kvinner. Median alder ved død var hhv. 71 år og
76 år. Til sammenlikning var median alder ved død for alle døde i Norge i 2005 80,5 år for menn og 85,5 år for kvinner (9).

Dødsårsaker i befolkningen som helhet $\mathrm{i}$ 2005 og underliggende dødsårsak hos de 1773 obduserte, basert på dødsmeldingen alene og etter justering ved obduksjon, er vist $\mathrm{i}$ tabell 1 (10). Obduksjonsresultatene medførte endring av underliggende dødsårsak for $1077(61 \%)$ av 1773 dødsfall. I 567 tilfeller (32\%) medførte endringene skifte av ICD-10-kapittel for dødsårsak. For $510(29 \%)$ medførte endringene skifte av dødsårsak innen samme ICD-10-kapittel. For de resterende 696 dødsfallene (39\%) var dødsårsaken uendret. Det var betydelige endringer når det gjaldt de to største sykdomsgruppene hjerte- og karsykdommer og kreft. Forskyvninger av koder mellom disse to gruppene og de øvrige ICD-10-kapitlene er vist i figur 1 . Av totalt 778 dødsfall som ble kodet som hjerte- og karsykdom etter obduksjon, var 238 (31\%) flyttet inn i kapitlet fra andre kapitler. I kapitlet for maligne svulster var antall dødsfall overført fra andre kapitler 83 av 450 (18\%).

Obduksjonsresultatet ga størst endring av ICD-10-kapittel for underliggende dødsårsak hos de yngste og de eldste aldersgruppene. Andelen kvinner som fikk endret sykdomskapittel var høyere enn andelen menn i alle aldersgrupper, unntatt $i$ gruppen $>90$ år: Kvinner versus menn $<30$ år: $38 \%$ versus $35 \%, 31-50$ år: $30 \%$ versus $23 \%, 51-70$ år: $28 \%$ versus $26 \%, 71-90$ år: $39 \%$ versus $32 \%,>90$ år: $40 \%$ versus $43 \%$.

\section{Sykdommer i sirkulasjonssystemet}

Det var en betydelig forskyvning av dødsårsaker innenfor kapitlet. Endringer som følge av obduksjon innen de tre hovedgruppene iskemisk hjertesykdom, hjerte- og karsykdommer av ikke-iskemisk årsak og cerebrovaskulære sykdommer i kapittel IX er fremstilt i figur 2. Antallet med iskemisk hjertesykdom som underliggende dødsårsak økte fra 309 til 443, eller fra $17 \%$ til $25 \%$ av alle dødsårsaker. Antallet dødsfall forårsaket av lungeembolier eller dyp venetrombose (i gruppen hjerte- og karsykdommer av ikke-iskemisk årsak) ble ikke endret etter obduksjon, men utskiftingen av tilfeller var stor. Samsvar ble funnet i bare fem av 22 dødsfall (fig 3a).

\section{Maligne sykdommer}

Obduksjonsfunn medførte at kreft kom inn som ny underliggende dødsårsak i 83 tilfeller, mens kreft ble fjernet som underliggende dødsårsak i 46 tilfeller (fig 1). I 48 av de 83 nye tilfellene var det ingen opplysninger om kreftsykdom på den opprinnelige dødsmeldingen. For endringer innenfor kapittel IIc,

Tabell 1 Underliggende dødsårsaker i 2005, for alle dødsfall og for dødsfall hvor det ble gjennomført sykehusobduksjon. Oversikten over alle dødsfall (2. kolonne) er basert på tall fra Statistisk sentralbyrå (10)

\section{ICD-10-kapittel}

I A 00-B99: Visse infeksjons- og parasittsykdommer

II C00-C99: Maligne svulster ${ }^{2}$

III D50-D89: Sykdommer i blod og bloddannende organer og visse tilstander som angår immunsystemet

IV E00-E90: Endokrine sykdommer, ernæringssykdommer eller metabolske forstyrrelser

V F00-F99: Psykiske lidelser og atferdsforstyrrelser

VI G00-G99: Sykdommer i nervesystemet

VII-VIII H0O-H95: Sykdommer i øye og øre

IX 100-199: Sykdommer i sirkulasjonssystemet

X J00-J99: Sykdommer i åndedrettssystemet

XI K00-K93: Sykdommer i fordøyelsessystemet

XII L00-L99: Sykdommer i hud og underhud

XIII M00-M99: Sykdommer i muskel- og skjelettsystemet og bindevev

XIV N00-N99: Sykdommer i urinveier og kjønnsorganer

XV 000-099: Svangerskap, fødsel og barseltid

XVI P00-P96: Visse tilstander som oppstår i perinatalperioden

XVII Q00-Q99: Medfødte misdannelser, deformiteter og kromosomavvik

XVIII R00-R99: Symptomer, tegn, unormale kliniske funn og labora-

toriefunn, ikke klassifisert annet sted

XIX-XX S-Y: Ytre årsaker, samlet

\section{Alle dødsfall \\ $\mathrm{n}=41152$}

Andel i prosent

1,9
25,7

0,6

3,8

3,2

$<0,01$

35,3

9,9

0,3

0,2

0,6

2,1

$<0,01$

0,2

0,3

4,3

5,9
Sykehusobduserte lunderliggende dødsårsak basert på dødsmeldingl $n=1773$

Andel i prosent

$$
4,9
$$

23,3

0,7

2,3

1,4

2,4

0,1

36,6

10,1

8,0

0,1

1,1

1,0

0

0,1

1,1

3,2

3,2
Sykehusobduserte lunderliggende dødsårsak basert på obduksjon] $n=1773$

Andel i prosent 3,2

25,4

0,4

1,4

0,3

2,0

0,1

43,9

8,9

7,7

0,1

0,7

0,8

0,1

0,1

1 Inkluderer også døde under to år. Gruppen er liten og med få unntak kodet i ICD-10-kapittel XVI og XVII

${ }^{2}$ Ikke inkludert D00-D48: in situ, benigne og usikkert malignitetspotensial. Dette medfører at summen i kolonnen for alle dødsfall ikke blir totalt $100 \%$ 
maligne svulster, dreide det seg om endring av primært utgangspunkt eller krefttype (55 tilfeller).

\section{Øvrige dødsårsaker}

Obduksjonsresultatene førte til et fall $i$ andelen dødsårsaker fra de øvrige ICD-10-kapitlene (tab 1).

Diabetes mellitus var oppgitt som underliggende dødsårsak på dødsmeldingen til 22 individer (fig 3b). Etter obduksjon ble underliggende dødsårsak endret hos 19 av disse.

Antall dødsfall grunnet psykiske sykdommer ble redusert fra 25 til fem (fig 3c). En større andel av reduksjonen skyldtes endring av diagnosen alkoholavhengighetssyndrom, som kodes som psykisk sykdom. Når det ved obduksjon blir påvist organskader, endres den psykiske diagnosen til alkoholindusert organskade. Av de ti tilfellene med alkoholavhengighetssyndrom på dødsmeldingen, ble bare én årsak stående uendret som psykisk sykdom. Tre ble kodet som alkoholindusert organskade (levercirrhose og kardiomyopati) og seks fikk diagnoser som ikke var relatert til alkoholmisbruk. Obduksjon avdekket også nye alkoholrelaterte dødsfall, men bare som organskader. Selv om bare ett dødsfall ble kodet som alkoholavhengighetssyndrom etter obduksjon, økte derfor likevel antall alkoholdødsfall fra 17 til 23.

Den andre store gruppen av psykiatriske diagnoser som ble endret etter obduksjonen var alle «demens»-diagnoser. Bare to av i alt åtte med uspesifisert demens fikk en organisk definert demenskode (Alzheimers sykdom) etter obduksjonen, de øvrige tilfellene ble kodet som hjerte- og karsykdom, lungesykdom eller infeksjon.

Ved samtlige seks dødsfall der epilepsi var underliggende årsak ifølge dødsmeldingen, ble det satt annen dødsårsak etter obduksjonen: kreft, subaraknoidalblødning, Alzheimers sykdom, Sjögrens sykdom, myopati og iskemisk hjertesykdom.

I samtlige ni tilfeller der underliggende dødsårsak var angitt som legemiddelbivirkning eller komplikasjon til medisinsk behandling, ble den endret til en sykdomskode etter obduksjonen (hjertesykdom, tromboembolisk sykdom, kronisk obstruktiv lungesykdom (kols), kreft eller fraktur). Obduksjonsfunn førte også til færre tilfeller av både pneumoni og kronisk obstruktiv lungesykdom som underliggende dødsårsak. Bare 17 av 70 pneumonidødsfall og 13 av 71 kolsdødsfall ble bekreftet ved obduksjonsfunn.

Antall dødsfall på grunn av sykdommer i urinveier og kjønnsorganer ble også kraftig redusert etter obduksjon. Alle 11 med symptomdiagnosen «nyresvikt» på dødsmeldingen fikk en spesifikk diagnose etter obduksjon.

Sykehusobduksjon førte til et fall i antallet døde av ukjent årsak, kapittel XVIII, fra 56 til seks (tab 1). 34 av disse (61 \%) fikk påvist iskemisk hjertesykdom eller annen kardiovaskulær sykdom som dødsårsak.

Ved 18 av 37 dødsfall hvor underliggende dødsårsak etter obduksjon var oppgitt som fraktur grunnet fall, var ulykken oppgitt på dødsmeldingen. Like mange $(n=18)$ fikk fjernet fraktur grunnet fall som underliggende dødsårsak etter obduksjon og ble overført til kapittel for annen sykdom.

\section{Diskusjon}

Dødsmeldinger og obduksjonsrapporter danner grunnlaget for den offentlige dødsårsaksstatistikken som årlig publiseres av Statistisk sentralbyrå. Statistikken danner basis for vurderinger av folkehelsen. Det er derfor viktig at registeret holder høy kvalitet.

Siden obduksjonsfunn medførte endring av underliggende dødsårsak for hele $61 \%$ av dødsfallene og dødsårsak fra annet ICD-10kapittel hos $32 \%$, viser denne undersøkelsen at det er svært stor usikkerhet knyttet til dødsårsaksbestemmelse. Selv om antallet dødsfall hvor det ble uført sykehusobduksjon er lite $(n=1773)$ i forhold til totalt antall dødsfall $(n=41152)$, og utvalget er sterkt selektert, gir resultatene etter vår oppfatning grunnlag for diskusjon om kvaliteten på dødsårsaksstatistikken.

En svakhet ved de fleste obduksjonsstudier, inkludert vår egen, er at pasientmaterialet ikke er representativt for befolkningen som helhet. I vårt materiale er andelen dødsfall på grunn av infeksjon, psykisk sykdom og sykdom i fordøyelsessystemet en annen

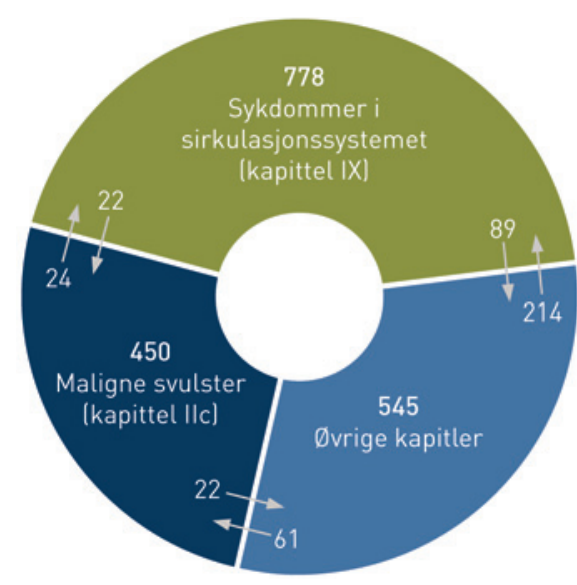

Figur 1 Endringer av ICD-10-koder for underliggende dødsårsak mellom kapittel IX, sykdommer i sirkulasjonssystemet, kapittel I/c, maligne svulster, og øvrige kapitler etter vurdering av obduksjonsresultat ( $n=1773$ ). Tallene $i$ kakestykkene viser det endelige antallet. Tallene ved pilene viser antall forflytninger mellom hovedgruppene

enn i populasjonen som helhet. Høyere andel av infeksjoner og sykdommer i fordøyelsessystemet $\mathrm{i}$ vårt materiale gjenspeiler at pasienter med slike sykdommer oftere dør mens de er innlagt i sykehus, mens den lave andelen psykiske sykdommer i hovedsak kan forklares ved at pasienter med uspesifisert demens, som kodes som psykisk

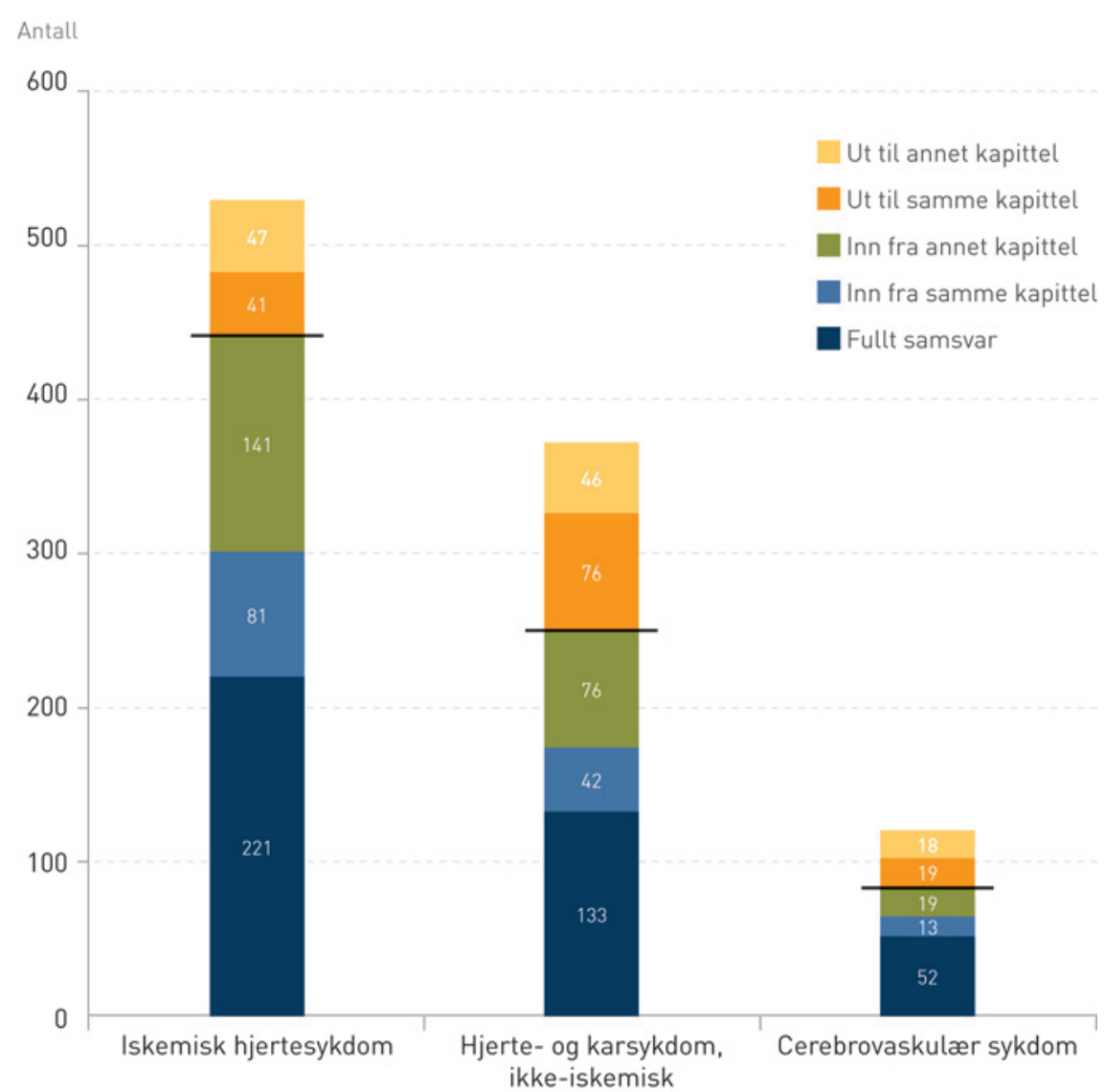

Figur 2 Endringer av ICD-10-koder for underliggende dødsårsak i kapittel IX, sykdommer i sirkulasjonssystemet. Iskemisk hjertesykdom: ICD-10 120-125. Hjerte-og karsykdom, ikke-iskemisk: ICD-10 100-15, 126-152, 170-199. Cerebrovaskulær sykdom: ICD-10 160-169. Den horisontale linjen over grønt felt i hver av de tre søylene markerer høyden på søylen etter justering for obduksjonsresultat. Tall i søylene = antall dødsfall 
sykdom, oftere dør på pleie- og sykehjem. Obduksjonsstudier er generelt også skjevfordelt hva angår kjønn og alder, det er en overvekt av menn og personer i yngre aldersgrupper $(11,12)$. At obduksjonsfrekvensen er lavere hos kvinner, kan forklares med at kvinner er eldre når de dør og at de derfor også har høyere sannsynlighet for å dø utenfor sykehus, på pleie- eller sykehjem.

$\mathrm{Vi}$ er ikke kjent med at det foreligger tilsvarende studier basert på ACME-systemet, men flere eldre sammenlikninger av dødsmelding og obduksjonsresultat har gitt tilsvarende funn. En studie fra Connecticut i 1980 viste at obduksjonsfunnene medførte endring av underliggende dødsårsak med skifte av ICD-kapittel i $29 \%$ av tilfellene (5). Obduksjonsfrekvensen i befolkningen i Connecticut var ikke oppgitt. En østtysk studie fra 1987 med tilnærmet $100 \%$ obduksjonsfrekvens viste at obduksjonsfunn medførte endring av underliggende dødsårsak og skifte av ICD-kapittel hos $30 \%$ (6).

At våre funn fra 2005 likner funn i eldre studier, kan tyde på at fremskrittene i diagnostiske metoder de siste tiårene ikke har gitt større samsvar mellom kliniker og obdusent når det gjelder dødsårsak. Det kan være at fallende obduksjonsrater har fort til at autopsi nå er forbeholdt særlig kompliserte sykdomsforløp der dødsårsaken er vanskelig å fastsette. De fleste pasienter i vårt materiale har imidlertid vært utredet ved regionsykehus, og legene har hatt tilgang til alle journaldata. At de obduserte i gjennomsnitt var nesten ti år yngre enn median alder ved død i befolkningen som helhet, impliserer også at aldersrelatert multimorbiditet i mindre grad har komplisert fastsettingen av underliggende dødsårsak i vårt materiale.

I tråd med tidligere undersøkelser fant vi en markert økning av dødsårsaker fra sykdommer i sirkulasjonssystemet (ICD-10kapittel IX) etter at vi hadde tatt hensyn til obduksjonsfunnene. Det har vært rapportert jevn nedgang i dødelighetsrater av hjerte- og karsykdommer de siste 40 årene (13). En oversiktsstudie fra 1998 om obduksjonens rolle for epidemiologiske studier av hjerteog karsykdommer konkluderte med at verken dødsmelding, klinisk journal eller intervju kunne erstatte obduksjon (14). Det meste av fallet i dødelighet av hjerte- og karsykdommer er utvilsomt reelt, men i en finsk studie om dødsårsaker hos middelaldrende menn ble det påpekt at det er viktig med høy obduksjonsrate (spesielt når det gjelder dem som dør utenfor sykehus) for å følge den videre utviklingen $\mathrm{i}$ dødelighet av hjerte- og karsykdommer (15). I Norge har fallet $i$ a

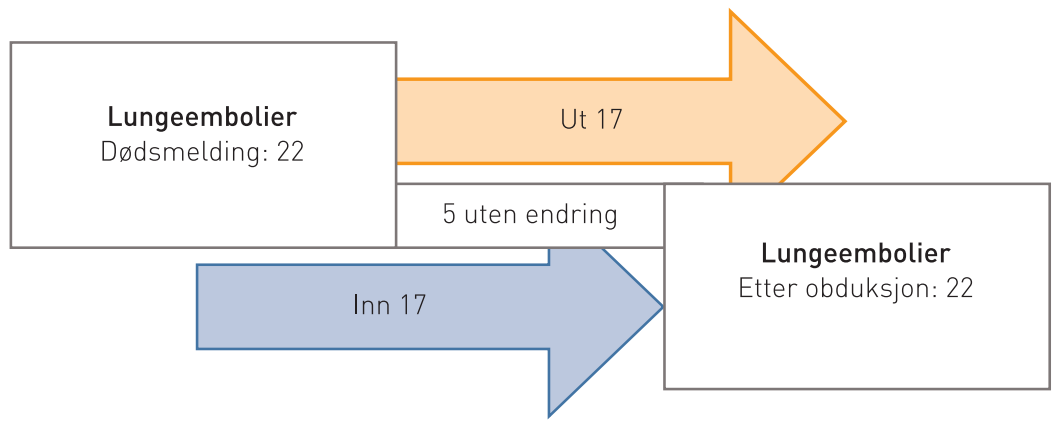

b

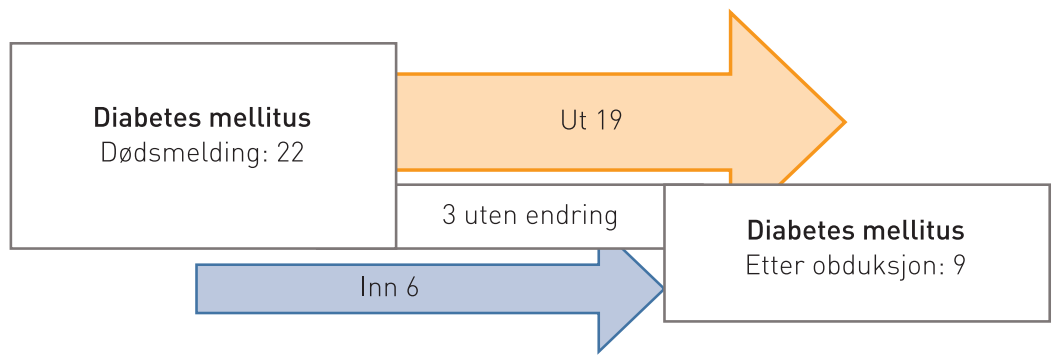

C

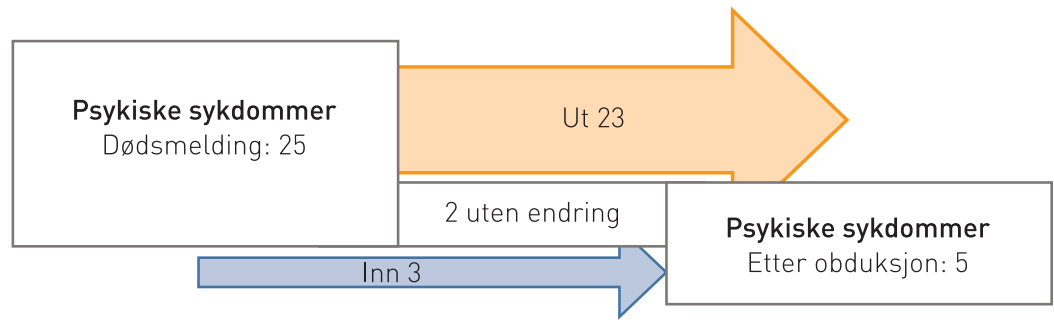

Figur 3 Endringer som følge av obduksjonsresultat for sykdomsgruppene a) lungeembolier: ICD-10 1269, b) diabetes mellitus: ICD-10 E100-149 og cl psykiske sykdommer: ICD-10 F011-480 dødelighetsratene av hjerte- og karsykdommer kommet samtidig med et sterkt fall $\mathrm{i}$ antall rettsmedisinske obduksjoner etter plutselig, uventet død (16).

Samsvaret mellom dødsmelding og obduksjonsresultat var høyest for dødsfall som skyldtes kreft. Likevel medførte obduksjonsfunn at rundt $10 \%$ av tilfellene der kreftsykdom var underliggende dødsårsak ut fra dødsmeldingen, ble omklassifisert til annen dødsårsak. Forskyvningen motsatt vei var imidlertid større, slik at kreftsykdommenes andel av alle dødsfall økte fra $23,3 \%$ til $25,4 \%$. Hvert tiende av disse krefttilfellene var ikke nevnt i dødsmeldingen. Disse funnene er i tråd med en studie fra Sverige fra 1997, der det ble rapportert at fallende obduksjonsfrekvens kan være årsak til insidensfall av flere krefttyper (11). De svenske forskerne advarte derfor mot å trekke konklusjoner om utviklingen i kreftforekomst uten å ta hensyn til forskjeller i obduksjonsrater.

Vi kan ikke utelukke at noen av dødsmeldingene er skrevet etter at foreløpige obduksjonsfunn foreligger. Dette vil i så fall medføre at vi underestimerer obduksjonens betydning for fastsetting av underliggende dødsårsak.

Dårlig kvalitet på dødsmeldinger og validiteten av dødsårsaksstatistikkene er hyppig diskutert (1). Artikler der man stiller spørsmål ved kvaliteten på obduksjonsresultatene er færre. Det er grunn til å minne om at obduksjonsresultatene ikke nødvendigvis alltid representer fasit. En undersøkelse fra 2006 om kvaliteten på obduksjonsrapporter i det britiske «coroner»-systemet for undersøkelse av dødsfall viste at $25 \%$ hadde dårlig eller uakseptabel kvalitet (17). I tillegg til å anbefale regelmessige kvalitetskontroller med annenhåndsvurdering (second opinion) var konklusjonen at det var behov for å definere en nasjonal standard for oppsett av dødsårsaker i obduksjonsrapportene.

Selv om britiske «coroner»-undersøkelser ikke er direkte sammenliknbare med norske sykehusobduksjoner, er det grunn til å merke seg at det heller ikke i Norge foreligger noen nasjonal standard for hvordan obduksjoner skal gjennomføres og resultater bedømmes. Ved rettslige likundersøkelser i Norge gjennomfører Den rettsmedisinske kommisjon en systematisk kvalitetskontroll (16). Innføringen av en nasjonal standard og systematisk kvalitetskontroll for sykehusobduksjoner ville kunne styrke obduksjonens rolle $\mathrm{i}$ vurdering av dødsårsaken.

Endringene i dødsårsak etter obduksjon kan tyde på at kliniker og patolog har ulik forståelse av oppsettet av dødsårsaker. Fravær av epilepsidødsfall og halvering av diabetesdødsfall etter obduksjon indikerer at patologer underdiagnostiserer dødsårsaker fra enkelte sykdomsgrupper. Lav bruk av klinisk-kjemiske tilleggsundersøkelser kan også bidra til at sykdommer uten morfologisk korrelat ikke kommer med blant obduksjonsdiagnosene. Ulik forståelse kan også ha 
sin bakgrunn i manglende kunnskap. En stor del av obduksjonsrapportene ferdigstilles sannsynligvis uten kjennskap til diagnosen $\mathrm{i}$ dødsmeldingen, som ofte utfylles av andre leger enn de som skriver obduksjonsbegjæringen. Hvis diskusjon av den klinisk angitte dødsårsaken på dødsmeldingen hadde vært fast prosedyre i obduksjonsrapporten, ville også tolkingen av de ulike diagnoser vært enklere for Dødsårsaksregisteret.

Det pågår nå planlegging av en ny elektronisk dødsmelding. I den sammenheng er det mulig å innføre endringer som kan bidra til å høyne kvaliteten på dødsårsaksregistreringen, inkludert registreringen av obduksjonsfunn. For eksempel kan man overveie om det er riktig at det er kodepersonalet ved Dødsårsaksregisteret som skal vurdere diagnoseoppsettet på obduksjonsrapporten mot diagnoseoppsettet i dødsmeldingene. I Finland er det legen som skriver dødsmeldingen og rekvirerer obduksjonen som er pålagt denne oppgaven (15).

\section{Konklusjon}

Funn ved obduksjon medførte at underliggende dødsårsak ble endret hos $61 \%$ av de sykehusobduserte i 2005. Hos $32 \%$ medførte endringen at dødsårsaken ble flyttet til nytt ICD-10-kapittel. Den høye endringsraten og den til dels betydelige flyttingen mellom de ulike sykdomsgruppene tilsier at obduksjon fortsatt er av vesentlig betydning for dødsårsaksstatistikken.

\section{G. Cecilie Alfsen (f. 1955)}

er spesialist i patologi og overlege/førsteamanuensis med fagansvar for obduksjoner ved Akershus universitetssykehus.

Ingen oppgitte interessekonflikter.

\section{Jan Mæhlen (f. 1952)}

er overlege i nevropatologi ved Oslo universitetssykehus, Ullevål, professor II ved Universitetet i Oslo og medisinsk konsulent ved Dødsårsaksregisteret, Nasjonalt folkehelseinstitutt. Ingen oppgitte interessekonflikter.

\section{Litteratur}

1. Alfsen GC, Lyckander LG, Lindboe AW et al. Kvalitetssikring ved dødsfall i sykehus. Tidsskr Nor Legeforen 2010; 130: 476-9

2. Rogde S. Hvor pålitelig er dødsårsaksstatistikken? Tidsskr Nor Legeforen 2009: 129: 980.

3. Svare A. Trenger vi virkelig flere obduksjoner? Tidsskr Nor Legeforen 2010; 130: 756-8.

4. Ellingsen CL, Mæhlen J. Heller flere enn færre obduksjoner. Tidsskr Nor Legeforen 2010; 130: 1121.

5. Kircher T, Nelson J, Burdo H. The autopsy as a measure of accuracy of the death certificate. N Engl J Med 1985; 313: 1263-9

6. Modelmog D, Rahlenbeck S, Trichopoulos D. Accuracy of death certificates: a population-based, complete-coverage, one-year autopsy study in East Germany. Cancer Causes Control 1992; 3: 541-6.

7. Om statistikken. Oslo: Statistisk sentralbyrå, 2010 www.ssb.no/vis/emner/03/01/10/dodsarsak/ om.html (20.12.2010).

8. International statistical classification of diseases and health related problems ICD. 10th revision, version for 2007. Genève: World Health Organiza- tion, 2007. http://apps.who.int/classifications/ apps/icd/icd10online/ (20.12.2010).

9. Dødelighetstabeller. Oslo: Statistisk sentralbyrå, 2005. www.ssb.no/dode/arkiv/tab2006-04-27-05.html (22.1.2011).

10. Dødsfall etter kjønn, alder og underliggende dødsårsak. Hele landet. 2005. Oslo: Statistisk sentralbyrå, 2007. www.ssb.no/dodsarsak/arkiv/ tab-2007-10-19-11.html (30.1.2011).

11. Lindström P. Janzon L, Sternby NH. Declining autopsy rate in Sweden: a study of causes and consequences in Malmö, Sweden. J Intern Med 1997; 242: 157-65.

12. Gulsvik AK, Gulsvik A, Svendsen E et al. Diagnostic validity of fatal cerebral strokes and coronary deaths in mortality statistics: an autopsy study. Eur J Epidemiol 2011; 26: 221-8.

13. Dødelighet av hjerte- og karsykdommer og svulster. 2000-2009. Oslo: Statistisk sentralbyrå, 2010. www.ssb.no/dodsarsak/fig-2010-12-03-01.html (25.1.2011)

14. Smith CJ, Scott SM, Wagner BM. The necessary role of the autopsy in cardiovascular epidemiology. Hum Pathol 1998; 29: 1469-79.

15. Lahti RA, Sarna S, Penttilä A. Exploitation of autopsy in determining natural cause of death: trends in Finland with special reference to the diagnostics of ischemic heart diseases and cerebrovascular diseases in middle-aged males, 1974-1993. Forensic Sci Int 1998; 91: 109-21.

16. Den rettsmedisinske kommisjon. Årsrapport 2009 www.justissekretariatene.no/nb/Innhold/DRK/ Arsmeldinger-og-veiledere/ (28.1.2011).

17. The coroner's autopsy. Do we deserve better? A report of the National Confidential Enquiry into Patient Outcome and Death NCEPOD (2006). www.ncepod.org.uk/2006.htm (28.1.2011).

Mottatt 31.3. 2011, første revisjon innsendt 9.6. 2011, godkjent 10.11. 2011. Medisinsk redaktør Mette Sagsveen. 